\title{
Planejamento de ensino na educação física - Uma contribuição ao coletivo docente
}

*Fabiano Bossle

\author{
A reflexão crítica sobre â prática se torna uma exigência da relação Teorial
}

Prática sem a qual a teoria pode ir virando blábláblá e a prática, ativismo.

(Freire, 1997)

\section{Resumo}

$O$ presente texto pretende refletir sobre o tema planejamento de ensino na educação física, inicialmente situando-o no contexto da educação - didática, na acepção de um uso mais abrangente, para então deslocar o olhar especificamente sobre $o$ âmbito da educação física e da particularidade desta como área de conhecimento e disciplina na escola. Minhas considerações ao longo do trabalho apontam no sentido de valorizar o estudo e a pesquisa, de questões didáticas/pedagógicas, como o planejamento de ensino enquanto elemento constitutivo e a ação de planejar como indispensável ao trabalho docente coerente e comprometido com a educação.

Descritores: Planejamento; Educação física; Ensino.

\footnotetext{
Abstract

The following text intents to reflecton the physical education planning theme, inicially placing it in the context of didatics-education in a wider usage, then focusing specifically on the issue in its peculiarity as a knowledge field and discipline at school. My consideration through this studygoes towards valuing study and research on didatic/pedagogical matters, such as the teaching planning as a constitutive element and the planning action as essential to the coherent-teaching staff work in volved with education.
}

Keywords: Physical education; Teacher effèctiveness.

\section{Introdução}

O planejamento, de um modo geral, diz respeito a intencionalidade da ação humana em contrapartida ao agir alatoriamente(Luckesi, 1992), ao "fazer de qualquer jeito", desconsiderando um fim, um objetivo, e um agir de forma organizada (os meios) para construir/atingir o resultado desejado. $\mathrm{O}$ planejamento de ensino, portanto, é uma construção orientadora da ação docente, que como processo, organiza e dá direção a prática coerente com os objetivos a que se propõe. Tem que responder às seguintes questões: -Ao como? Com quê ? O quê ? Para quê ? Para quem ? na forma de plano. Para que seja possível a concretização desta atividade docente, há a necessidade de uma outra instância de planejamento que são, o projeto político-pedagógico e o projeto curricular, que serão norteadores da ação docente coerente e responsável, e antecedem ao planejamento de ensino propriamente dito.

$\mathrm{Na}$ área de conhecimento da educação física, pelo menos nos periódicos mais expressivos, são muito poucos os artigos sobre o tema planejamento de ensino, como mostrarei a seguir em uma revisão bibliográfica que realizei, bem como, são poucos os autores que escrevem livros sobre a didática da educação física, e conseqüentemente sobre o planejamento de ensino. É possível afirmar que o assunto desperta pouco interesse na academia, e que também seria o planejamento uma questão "polêmica" (Molina Neto, 
O planejamento pode ser visto pela ótica, de, inicialmente atender as necessidades mais básicas do homem primitivo, ao se Essas e outras questões organizar para pautam este texto, não sobreviver, ou quanto no sentido de encontrar da necessidade de mas sim na busca de organização das uma reflexão sobre o primeiras civilizações, tema proposto, em de suas estruturas uma perspectiva diafuncionais, de suas lógica de entendimento cidades, e da desse elemento consorganização da titutivo do trabalho sociedade. docente do professor de educação física.

\section{O planejamento de ensino}

Planejamento. S.m. 1. Ato ou efeito de planejar. 2. Trabalho de preparação para qualquer empreendimento, segundo roteiro e métodos determinados; planificação: o planejamento de um livro, de uma comemoração.

Apresentei acima a conceituação do termo pelo Dicionário Aurélio para inicialmente esclarecer sobre o que estou escrevendo, e para mostrar que o conceito supra citado se refere ao antecipar mentalmente uma ação, ou um conjunto de ações a ser realizada (Vasconcellos, 1995), ou seja, uma ação que visa um fim, referida a um dado contexto a ser transformado, de forma que o sujeito esteja comprometido com a concretização do que foi elaborado. Planejar faz parte do ser humano, a partir da interação com a natureza e com os demais seres, de identificação das necessidades e concretização das mesmas, de forma racional. O planejamento pode ser visto pela ótica de, inicialmente atender as necessidades mais básicas do homem primitivo, ao se organizar para sobreviver, ou quanto da necessidade de organização das primeiras civilizações, de suas estruturas funcionais, de suas cidades, e da organização da sociedade.

Para introduzir a questão do planejamento no âmbito da educação escolar, faz-se necessário, a abordagem das diferentes concepções do processo de planejamento, de acordo com cada contexto sócio-político-econômico-cultural ao longo da história da educação escolar. Nesse sentido, Ott (1984) faz referência a três fases do planejamento. A primeira fase é a do princípio prático sem grande preocupação formal e, tendo como objetivo atender as atividades de aula exclusivamente. A Segunda é a fase instrumental, que está relacionada à uma tendência tecnicista de educação, como solucionar os problemas de falta de produtividade da educação escolar, sem considerar contudo os fatores sócio-político-econômicos. A terceira, e última é a fase do planejamento participativo, que buscou na resistência ao modelo de reprodução do sistema educacional, valorizar a construção coletiva, a participação e a formação da consciência crítica a partir da reflexão sobre a prática transformadora.

Segundo Veiga Neto (1993), ao se referir a acepção micro $^{1}$ do planejamento da educação no Brasil, podemos identificar duas vertentes, uma tecnicista e outra participativa ou crítica. Sendo a primeira a que pressupõe uma dada importância ao método positivista, ou que deram (ou ainda dão?) ênfase ao produto, em detrimento do processo, sendo o primeiro (produto) de má qualidade (Balzán, 1996). Os exemplos referentes a essas tendências no Brasil, são encontrados em literaturas como: "Planejamento de Ensino e Avaliação", de Turra, et ali., 1975-1998, "Didática. Uma Introdução", de Nérici, 1985, "Didática Geral", de Martins, 1986. Já a segunda, mais recente, apresenta um "compromisso com um projeto político-pedagógico progressista para a escola e a sociedade brasileiras" (Veiga Neto, 1993), pressupondo uma postura crítica e participativa, de competência e engajamento.

Em relação a postura crítica, que vai em sentido contrário a burocratização e aos modelos sistêmicos, o planejamento não pode ser encarado como ação puramente formal, mas como uma ação viva e decisi- 
va, pois é um ato político decisório, como bem coloca Luckesi (1990):

"O planejamento, entendido como ato político, será dinâmico e constante, pois estará afeito a uma constante tomada de decisão. Não necessariamente deverá ser registrado em documento escrito. Poderá tão somente ser assumido como uma decisão e permanecer na memória viva como guia de ação. Aliás, só como memória viva ele faz sentido. Papéis e formulários são simplesmente mecanismos de registro e fixação gráfica do decidido."

Geralmente há dificuldades no âmbito escolar, com a distinção entre plano e planejamento, como forma de esclarecimento dos termos aqui usados. Por planejamento entendo o processo de reflexão, racionalização, organização e coordenação da ação docente, que visa articular a atividade escolar e a problemática do contexto social. Já o plano é o produto, que pode ser explicitado na forma de registro, de documento ou não.

A didática, através de diferentes autores faz distinção entre os tipos e/ou níveis de planejamento. Sendo que por planejamento do sistema de educação, ou educacional o que se refere as grandes políticas educacionais, em nível nacional, estadual e municipal, o planejamento da escola, ou seja, o projeto educativo (político-pedagógico) da instituição, o planejamento curricular, que segundo Gimeno Sacristán (1998), é a função de ir formando progressivamente o curriculo em diferentes etapas, fases, ou através das instâncias que o decidem e moldam, e finalizando, o planejamento de ensino (objeto de estudo deste ensaio), de ensino-aprendizagem (Vasconcellos, 1995), ou planejamento escolar (Libâneo, 1994), que é o mais próximo da prática do professor e da sala de aula. O planejamento de ensino propriamente dito, se expressa na organização intencional do professor para atender as necessidades do cotidiano escolar, pode ser subdividido em plano de disciplina, ou de curso, que é o plano que se faz para um ano ou se-

As ações planejadas são fruto de reflexões críticas sobre o próprio trabalho docente, quando inserido em uma comunidade com características e necessidades próprias a serem atendidas de forma consciente e objetiva, assumindo em sua prática pedagógica o ato da educação em seu sentido mais pleno, como aro ou efeito de educar (se), considerando o envolvimento e a participação dos educandos e educadores na construção do fazer educativo e de seus processos.

\section{Planejamento de ensino - Uma revisão nos periódicos nacionais da educação física}

Com o conhecimento de que o trabalho docente exige do professor tempo e dedicação, em função de todas as atividades que o envolvem, sendo 
planejamentos, aulas, reuniões, avaliações e demais atividades da escola que sobrecarregam os professores em muitas situações, e mesmo no seu cotidiano, sempre há que se encontrar espaço para revisar, planejar, e organizar sua prática pedagógica. A didática, seja na formação profissional, seja na qual nos confrontamos em nosso cotidiano, dedica-se ao longo dos anos, ao estudo e aprofundamento do elemento ou ferramenta planejamento de ensino, como forma de orientação, cumprindo com o seu propósito de dar suporte e respostas baseados nos referenciais teóricos sobre a prática.

Por outro lado, o planejamento de ensino no âmbito da educação física é uma questão que não vem merecendo a atenção dos estudiosos e pesquisadores da área. Digo isso em função da revisão bibliográfica que realizei na biblioteca da Escola de Educação Física da Universidade Federal do Rio Grande do Sul sobre o tema planejamento de ensino. Procurei nos periódicos de maior expressão no âmbito da produção científica da pesquisa em educação física, do ano de 1994 até 2000, sendo eles:

$\begin{array}{ll}\text { Revista Mineira de Educação Física } & 1994-1996 \\ \text { Revista Artus } & 1996-1999 \\ \text { Revista Perfil } & 1997-2000 \\ \text { RevistaPaulistade Educação Física } & 1994-1998 \\ \text { Revista Movimento } & 1994-2000 \\ \text { Revista Brasileira de Ciências do Esporte } & 1994-2000 \\ \text { Revista Motus Corporis } & 1998-2000 \\ \text { Revista Motriz } & 1995-2000 \\ \text { Revista de Educação Física da U.E.M. } & 1994-2000 \\ \text { Revista Kinesis } & 1994-2000 \\ \text { Revista Motnvivência } & 1994-1999 \\ \text { Revista Conexões } & 1998-1999\end{array}$

Revista da F.M.U.

19942000

Revista Paranaense de Educação Física 1996-1997

Perspectivas em Educação Física Escolar 1996-1997

Nesta revisão nos principais periódicos no âmbito da educação física, foram encontrados 2 artigos apenas sobre planejamento, sendo "Considerações Organizacionais para o Planejamento Efetivo de uma Aula", de Ruy Jornada Krebs, referente à um programa de educação física para crianças, sobre a abordagem construtivista, explicitando os passos recomendados na organização, considerando os elementos necessários como agrade curricular, o plano anual, os planos periódicos, planos semanais e planos diários, de forma bastante didática e explicativa. O segundo artigo encontrado foi "Planejamento Participativo e o Ensino de Educação Física no $2^{\circ}$ Grau", de Walter Roberto Correia, sendo este um relato de experiência do autor na rede pública estadual de São Paulo sobre a organização coletiva das aulas de educação física com um determinado grupo de alunos, sem entrar no assunto específico do planejamento participativo, apenas um relato.

Ainda sobre a revisão do tema planejamento de ensino nos periódicos de educação física, encontrei 4 resumos de apresentações em grupos de trabalhos temáticos do X Combrace (1997), sendo que todos tratavam a questão do planejamento pedagógico na perspectiva democrática do planejamento participativo, considerando a participação como exercida na colaboração, na decisão e na construção em conjunto (Gandim, 1994).

Sobre o planejamento participativo, em uma concepção de aulas abertas, Cardozo (1998), considera a possibilidade da co-decisão nos nivveis de planejamen to, objetivos, conteúdos e formas de transmissão e comunicação no ensino, criticando o excesso de tecnicismo na área de educação física e propondo a alternativa da flexibilidade nas decisões e ações do fazer pedagógico, dedicando ao planejamento considerações importantes como a construção coletiva. Este artigo

\section{Movimento}

Movimento, Porto Alegre, V. 8, n. 1, p. $31-39$, janeiro/abril 2002 
está inserido no livro "Didática da Educação Física1", e como propõe o título, dedica-se à reflexão do fazer pedagógico na área da educação física, contribuição essa de extrema importância para o trabalho docente do professor de educação física.

O organizador do livro supra citado, Elenor Kunz creio que seja um dos poucos autores da área que demonstra interesse, atualmente, em publicar e discutir questões didáticas da educação física, como o planejamento de ensino, por exemplo. Este autor faz considerações importantes sobre o movimento humano e a escola, criticando a instrumentalização e reafirmando o compromisso do professor e da disciplina enquanto prática pedagógica, percebe-se isso claramente em seus livros "Educação Física: ensino e mudanças" (1991), em que faz uma comparação entre o planejamento de ensino e o plano anual de dois professores de educação física, um da escola pública e outro da escola privada, em uma concepção micro, e em uma concepção macro de ensino, quando discute as Diretrizes Curriculares e o planejamento para a educação física de $\mathrm{I}^{\mathrm{o}}$ grau, mostrando a importância desta para o planejamento do professor, das tomadas de decisões com base nessas referências. Já em "Transformação DidáticoPedagógica do Esporte" (1994), defende o esporte como objeto/conteúdo de uma aprendizagem significativa pela educação física escolar, e importante, sem que desmereça outras objetivações culturais que integram o amplo leque de opções utilizáveis pela educação física.

Considero que a baixa produção de trabalhos, e a dedicação sobre o planejamento de ensino no âmbito da educação física, como um fato que mereça atenção da comunidade científica, em vista da presente produção científica da área, e principalmente pelo pouco interesse que o assunto aparentemente tem despertado nesta comunidade. Visto que, grande parte da produção científica da área se desenvolve em temas que abrangem o movimento humano por um viés de estudo biomecânico, cinesiológico, fisiológico, postural, em detrimento dos estudos que abordem questões da relação entre o professor de educa- ção fisica e a escola. De forma alguma classifico como mais importante esta ou aquela abordagem, apenas faço referência a quase ausência, e a necessidade de que se desenvolvam estudos que possam contemplar a prática pedagógica e a didática de ensino do licenciado em educação física, bem como, do planejamento de ensino.

\section{O planejamento dos professores de educação física como uma atribuição "polêmica"}

O planejamento de ensino, ou planejamento pedagógico - o que está mais próximo da prática pedagógica e para ela desenvolvido - tem na figura do professor um agente privilegiado de transformação da realidade, relacionada ao interesse e a complexidade ${ }^{2}$ da ação a ser desenvolvida. Por ser o trabalho docente exigente - formador - exige planejamento à altura, para evitar o que alguns autores chamam de "improvisação ou acaso" (Gandin, 1991 - Karling, 1991 - Libâneo, 1994 - Gandin e Cruz, 1995 Vasconcellos, 1995). Ao mesmo tempo, surge o questionamento dos professores em geral sobre o por quê do planejamento de ensino e da sua expressão escrita na forma de planos, o "planejar para quê?" (Fleuri, 1987), e "porquê?" (Corazza, 1997), sendo que muitos professores ainda associam o planejamento e a realização de planos como um trabalho burocrático desnecessário. Nesse sentido, para MolinaNeto (1996), a realização de planos para os professores de educação física:

\footnotetext{
"(...) é possivelmente uma das tarefas pelas quais os professores de educação física divergem da cultura das escolas. De um lado a cultura escolar opera e da forma a sua estrutura com base na escritura, por outro lado o coletivo, como já demonstrei, opera com a palavra oral e a linguagem corporal. O coletivo considera a tarefa de fazer planos escritos pouco necessária e uma tarefa feminina."
} 
De acordo com este estudo ${ }^{3}$ fazer programação escrita é uma questão polêmica e ..., feminina, como aparece na citação acima. Não vou abordar a questão da condição feminina a que o autor se refere dentro da escola, sendo que ele próprio classifica como machista, porque não é o objetivo deste ensaio discutir esse processo sexista dentro da escola, necessitando outros leituras e abordagens, ficando este limitado a questão polêmica do planejamento de ensino/planos de aula.

É ressaltado no referido estudo que o trabalho Para que possa haver docente do professor de participação nas educação física é baseado tomados de decisões, é no fazer, desta forma jusnecessário ter clara a tificando a polêmica em is torno do ato de visão de processo, da construção do planecaminhada para jamento e de escrever atingir os objetivos, planos de aula. Considero sendo que estes devem importante questionar, necessariamen te ser inicialmente, que coerentes com o orientações sobre o projeto político — $-\begin{aligned} & \text { planejamento de ensino o } \\ & \text { professor de educação }\end{aligned}$ pedagógico da escola. física tem no seu curso de graduação, enquanto ainda estudante, seja nas disciplinas de metodologia do ensino da educação física, seja na importante didática da educação física, com suas orientações referidas à uma teoria didática específica à prática pedagógica da área. Ao passo que ao longo, ou pelo menos no final do curso de graduação, terá que organizar suas aulas nas disciplinas de prática de ensino, podendo se defrontar com dificuldades comuns às aulas improvisadas, o que certamente, não é uma experiência positiva. Dessa forma, independentemente de ser professor de educação física formado há pouco ou mais tempo, consideraria a seguinte questão:

\section{Que concepção de planejamento de ensino tem os professores de educação física?}

O planejamento de ensino dos professores de educação física considera um objeto de estudo baseado na cultura corporal, não raras vezes limitado às aulas práticas. Considero que é neste ponto que este coletivo se difere dos demais da escola na questão do planejamento de ensino, há uma "liberdade"/flexibilidade maior para programar e organizar sua prática pedagógica, baseando-me principalmente no plano de aula (produto), em que o professor pode estabelecer o que vai realizar naquela aula. Fica aqui caracterizado um movimento do professor no ato de planejar que considero importante destacar, que é a centralização da decisão do o quê fazer, podendo estar vinculado aos interesses únicos do professor, desconsiderando desta forma, a participação preciosa dos alunos nas decisões.

Para que possa haver participação nas tomadas de decisões, é necessário ter clara a visão de processo, da caminhada para atingir os objetivos, sendo que estes devem necessariamente ser coerentes com o projeto político - pedagógico da escola. O coletivo precisa da referência do projeto para construir a participação de todos, e acima de tudo, vivenciar a participação nas decisões que estabelecem os pressupostos dessa educação que a escola ou instituição quer. A partir dessa etapa, o coletivo constrói o seu planejamento de ensino, quer seja o plano de curso, de unidade ou o plano de aula, este último individual, e coerente com o projeto político - pedagógico e o contexto escolar.

Considero que há por parte dos professores de educação física, descrença no planejamento de ensino, manifestada por uma resistência ao colocar no papel o que se deseja. Há que se considerar a prática negativa, ou equivocada de realizar planejamento, muito comum há pouco tempo atrás nas escolas, onde os planos eram uma tarefa mecânica, para cumprir um ritual de formalidade, completamente sem sentido e freqüentemente de controle de atividades ditas como necessárias à escola, cobrados por coordenadores, orientadores e supervisores. A resistência a este discurso burocrático, foi uma prática de negação ao planejamento, não menos equivocada e baseada no 
discurso de que planos são entregues e engavetados, são copiados de livros, de colegas ou de um ano para outro, que a prática não leva em conta o que foi colocado no plano..., considerando desta forma o planejamento como desnecessário.

Penso que aconteça também o que chamaria de "vício" do professor de educação física na questão do planejamento de ensino, que é o fato de considerar que seu tempo de experiência como professor substitui o planejamento, e que o mesmo é para quem está começando a dar aulas. Penso que a experiência seja importante para qualquer ação humana, na medida em que se já nos defrontamos com aquela situação, já temos elementos a considerar para reconstruir nossa ação e consequentemente, atingir os objetivos a que nos propusemos. Acrescentamos elementos, não os consideramos como acabados na educação física, a prática do planejamento participativo é um exemplo pertinente, pois a construção se dá no sentido da flexibilidade de discutir as idéias de todos para a ação coletiva, a participação.

\section{Considerações finais}

Ao longo deste ensaio procurei refletir sobre questões que considero importantes sobre o tema planejamento de ensino, mais especificamente no âmbito da educação física. Esta reflexão, como coloco na introdução, é baseada no olhar de um professor de educação física preocupado com as questões didático - metodológicas que envolvem a ação docente deste coletivo, que entendo no momento como negligenciadas em detrimento de outros estudos deste amplo campo de pesquisa. Possibilitando desta forma que, nos equivoquemos ainda hoje, com uma possível discussão sobre a necessidade do planejamento de ensino na educação física.

Não é possível imaginar uma ação pedagógica sem planejamento, improvisada. $\mathrm{O}$ ato de planejar é intrínseco à educação (Padilha, 2001). O professor com claras idéias de seus objetivos e da sua responsabilidade para concretizá-los, deve planejar adequadamente suas tarefas (Alujas, 1980). Ter clareza em relação ao processo de construção do planejamento, dos meios para atingir os fins, da coerência com o projeto político - pedagógico, do contexto sócio econômico - cultural - político e da participação coletiva nas tomadas de decisões.

Considerar que o professor de educação física planeja sua ação docente diferente, porque não escreve, mas mentaliza simplesmente o que vai fazer, é no meu entender, uma das considerações sobre a possibilidade e a necessidade de estudo referente a particularidade dessa programação, seja em nível de planos de aula, sem desconsiderar os demais níveis de planejamento de ensino -plano de curso e de unidades - que orientam a prática pedagógica desse coletivo docente.

Penso que não seja necessário que o professor de educação física "preencha formulários" ao organizar sua prática pedagógica, pois estes servem apenas para entregar para orientadores/coordenadores, para que possam ter elementos de controle sobre o trabalho e o coletivo docente. Menos ainda, que não haja um registro do que se planeja, que aconteça simplesmente uma organização mental das atividades, pois desta forma, fica o dito pelo não escrito, a prática pela prática apenas, quando a sua justificativa (organização/previsão dos objetivos) se baseia em si própria, dificultando ao longo do processo de execução a sua avaliação e a do próprio processo.

Por fim, acrescento que a relevância do planejamento de ensino resida no fato de ser necessário à ação docente do professor de educação física, e como tal ser merecedor de estudos e pesquisas que possibilitem não somente a reflexão sobre o tema, mas considerar possibilidades de fazer planejamento diferentemente do modelo burocrático e sem sentido. Esta nova concepção deve necessariamente afirmar a sua importância no cotidiano, do comprometimento do professor com a sua ação educativa crítica e reflexiva, e a concretização dos objetivos existentes nas pro-

\section{7}

Movimento, Porto Alegre, V. 8, n. 1, p. $31-39$, janeiro/abril 2002 
postas pedagógicas construídas pelas escolas (Lei de Diretrizes e Bases da Educação - LDB - Lei no 9394/ 96, art. 12, parágrafo I).

Desta forma, espero que minhas considerações possam contribuir com o debate sobre questões da prática pedagógica dos professores de educação física, as observações que fiz foram no sentido de defender um posicionamento pessoal referente à um assunto que considero como pertinente e negligenciado na produção científica da educação física até este momento.

\section{Referências bibliográficas}

ALUJAS, A J.M. Accion Docente Del Professor de Educación Fisica. Em: apuntes de Medicina esportiva. Vol. XVII, $\mathrm{n}^{\circ} 68,1980$.

BALZAN, Newton Cézar. O Conceito de Planejamento e sua Aplicação aos Sistemas Educacionais e às Atividades de Ensino. Alcance e Limites ni Limiar do Século XXI. Em: Educação Brasileira. Brasília, D.F.: Vol. 18, ${ }^{\circ}$ 37, p. 151 - 172, julho - dezembro -1996.

CARDOZO, CL. Considerações de Aulas Abertas. Em: Kunz, Elenor (org.). Didática da Educação Física. Ijuí, R.S., Ed. UNIJUÍ, p.121-154,1998.

CORREIA, W.R. Planejamento Participativo e o Ensino de Educação Física no $2^{\circ}$ grau. Em: Revista Paulista de Educação Física. São Paulo: supl. 2,43-48.1996.

CORAZZA, Sandra Mára. Planejamento de Ensino como Estratégia de Política Cultural. Em: Moreira, A.F.B. (org.) Currículo: Questões Atuais. Campinas, S.P.: Papirus, p. 103-143,1997.

FREIRE, Paulo. Pedagogia da Autonomia: saberes necessários à prática educativa. São Paulo, Paz e Terra, 1997. $2^{\mathrm{a}}$ ed.

GANDIN, Danilo. Planejamento como Prática Educativa. São Paulo: Loyola, 1991. , e CARRILHO CRUZ, Carlos H.
Planejamento na Sala de Aula. Porto alegre: La Salle, 1995.

. A Prática do Planejamento Participativo.

Petrópolis, RJ.:Vozes, 2000 - $8^{\text {a }}$ ed.

GIMENO SACRISTÁN, J. e PÉREZ GÓMEZ, A I. Compreender e Transformar o Ensino. Porto Alegre: ArtMed, 1998.

KARLING. A A A Didática Necessária. São Paulo: IBRASA, 1991.

KREBS, RJ. Considerações Organizacionais para o Planejamento Efetivo de uma Aula. Em: Revista Metropolitana de Ciências do Movimento Humano/Faculdades Metroplitanas Unidas F.M.U., ${ }^{\circ}$ 3, p. 17-30,1997.

KUNZ, Elenor. Educação Física: Ensino e Mudanças. Coleção Educação UNIJUÍ; 11. Ijuí, RS. 1991.

LDB: Lei de Diretrizes e Bases da Educação - Lei No 9394/96.

, Transformação Didático - pedagógica do Esporte. Ijuí, R.S. Ed. UNIJUÍ, 1994.

LIBÂNEO, J.C. Didática. São Paulo: Cortéz, 1994.

LUCKESI, C.C. Filosofia da Educação. São Paulo: Cortéz, 1990.

, Planejamento e Avaliação na Escola:

Articulação e necessária determinação Ideológica. Em: O Diretor - articulador do projeto da escola. Série Idéias, $n^{\circ} 15$, são Paulo, F.D.E., p. 115 - 125, 1992.

, Planejamento, Execução e Avaliação do Ensino - a busca de um Desejo. Em: Revista da FAEEBA, ano 2, n 2, p. 137 -152, 1993.

MARTINS, J.P. Didática Geral: Fundamentos, Planejamento, Metodologia e Avaliação. São Paulo, Atlas, 1985.

MOLINA NETO, Vicente. La Cultura Docente Del Professorado de Educación física de Las Escuelas Publicas de Porto Alegre. (Tese de Doutorado) Barcelona: Universidad de Barcelona, 1996.

NÉRICI, C. A. Didática: Uma Introdução. São Paulo, Atlas, 1985.

OTT, Margot B. Planejamento de Aula: Do 
Circunstancial ao Participativo. Em: Revista de Educação da AEC. Brasília, D.F.: ano 13, $n^{\circ} 54$, p. $30-40,1984$.

PADILHA, P.R. Planejamento Dialógico: Como construir o projeto político-pedagógico da escola. Ed. Cortez, São Paulo - S.P. 2001.

TURRA, C.M.J.; ENRICONE, D.; SANTANNA, F.M.; ANDRÉ, L.C. Planejamento de Ensino e Avaliação. Porto Alegre: Sagra - Luzzato, 1998.11 ${ }^{\mathrm{a} e d .}$

VASCONCELLOS.C.S. Planejamento. Plano de Ensino - Aprendizagem e Projeto Educativo. Em: Cadernos Pedagógicos do Libertad - 1. 1995.

VEIGA NETO, A J. Planejamento e Avaliação Educacionais: Uma Análise Menos Convencional. Em: Cadernos do DEC. $\mathrm{N}^{\circ}$ 5, p. 12 - 28, UFRGS/FACED, dezembro, 1993.

* Mestrando no Programa de Doutorado e Mestrado em Ciências do Movimento Humano, na Escola de Educação Física da Universidade Federal do Rio Grande do SulUFRGS, Porto Alegre, R.S.

Recebido em: 01.10 .01

Revisadoem:25.02.02

Aceito em: 04.03.02

\section{Notas}

1 Para o autor a acepção macro do planejamento educacional no Brasil, diz respeito a um modelo sistêmico, governamental, e a acepção micro em nível escolar, ou mesmo de sala de aula.

2 Vasconcellos (1995), coloca que esta complexidade pode vir, basicamente, em função do objeto - complexidade da atividade em si

- e do processo - se o processo da atividade a ser desenvolvida for coletivo, demanda maior articulação, organização e registro.

3 Tese de Doutorado de Vicente Molina Neto

- La Cultura Docente Del Professorado de Educación Fisica de Las Escuelas Públicas de Porto Alegre. Barcelona, 1996. 
